\title{
Avaliação de
}

programas sociais: uma análise do impacto do Programa Bolsa Família sobre o consumo de alimentos e status nutricional das famílias ${ }^{1}$

Juliana Carolina Frigo Baptistella²

1 Este trabalho é derivado da dissertação de mestrado realizada na Universidade Federal de São Carlos (UFSCar) e vencedora do V Prêmio SOF de Monografias no tema Qualidade do Gasto Público. A autora agradece à professora Andrea Rodrigues Ferro pela orientação na dissertação do mestrado e aos professores Elaine Toldo Pazello e Alexandre Nunes de Almeida pelos comentários e sugestões.

2 Mestre em Economia Aplicada pela Universidade Federal de São Carlos (UFSCar). 


\section{Resumo}

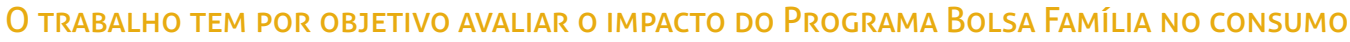
DE ALIMENTOS DAS FAMÍLIAS BENEFICIADAS. DADO OUE OS BENEFICIÁRIOS SÃO FAMÍLIAS POBRES E EXTREMAMENTE POBRES, OUAL A CONTRIBUIÇÃO DO PROGRAMA ONUANTO À SEGURANÇA ALIMENTAR DESSAS FAMÍLIAS, OU SEJA, OUUAL A SUA COLABORAÇÃO PARA OUUE AS FAMÍLIAS SAIAM DA SITUAÇÃO DE INSEGURANÇA ALIMENTAR? SÃo UTILIZAdos DAdos dA PESOUUISA DE ORÇAMENTOS FAMILIARES 2008/2009, REALIZADA PELO INSTITUTO BRASILEIRO DE GEOGRAFIA E ESTATísTICA, OUANTO AO CONSUMO DE ALIMENTOS DAS FAMÍLIAS BENEFICIADAS (GRUPO DE TRATAMENTO) E NÃO BENEFICIADAS (GRUPO DE CONTROLE) PELO PROGRAMA. A PARTIR DO MÉTODO DE PROPENSITY SCORE MATCHING, REALIZA-SE O PAREAMENTO ENTRE AS FAMÍLIAS, DE MODO OUE SE POSSAM COMPARAR UNIDADES DE OBSERVAÇÃO MUITO SEMELHANTES OQUANTO ÀS SUAS CARACTERÍSTICAS OBSERVÁVEIS. VERIFICA-SE OUE O PROGRAMA CONTRIBUI PARA AUMENTAR O CONSUMO DE ALIMENTOS DAS FAMÍLIAS BENEFICIADAS, PRINCIPALMENTE DOS ALIMENTOS OUUE FAZEM PARTE DA CESTA BÁSICA BRASILEIRA, UMA VEZ OUUE ESTAS FAMÍLIAS APRESENTARAM GASTOS MAIS ELEVADOS E SIGNIFICATIVOS DO OUUE AS FAMÍLIAS OQUE NÃO SÃO BENEFICIADAS. QUANTO AO IMPACTO NO STATUS NUTRICIONAL, DESTACA-SE OUUE O PROGRAMA COLABORA PARA ELEVAR A PERCENTAGEM DE CRIANÇAS E ADOLESCENTES COM ÍNDICE DE MASSA CORPORAL NORMAL E DE ADULTOS COM OBESIDADE, RESULTADOS OUE INDIRETAMENTE PODEM SER ASSOCIADOS COM A SITUAÇÃO DE SEGURANÇA ALIMENTAR.

\section{Abstract}

THIS THESIS AIMS TO EVALUATE THE IMPACT OF THE BOLSA FAMILIA PROGRAMME IN FOOD CONSUMPTIONOF ATTENDED FAMILIES. GIVEN THAT THE BENEFICIARIES ARE POOR AND EXTREMELY POOR FAMILIES, WE WANT TO KNOW WHAT ARETHE PROGRAM'S CONTRIBUTIONFOR SECURITY OF THESEFAMILIES. WE USED DATA FROM THE PESQUISA DE ORÇAMENTOS FAMILIARES 2008/2009, CONDUCTED BY THEINSTITUTO BRASILEIRO DE GEOGRAFIA E EStatística, RELATED TO FOOD CONSUMPTIONOF THE BENEFICIARY (TREATMENT GROUP)AND NON-BENEFICIARY (CONTROL GROUP) FAMILIES. USING PROPENSITY SCORE MATCHING METHOD WAS POSSIBLE TO COMPARE FAMILIES VERY SIMILAR INTHEIROBSERVABLE CHARACTERISTICS.WE HAVE FOUND THAT THE PROGRAM CONTRIBUTES TO INCREASE FOOD CONSUMPTION OF BENEFICIARY FAMILIES, ONCE THESE FAMILIES PRESENTED STATISTICALLY AND SIGNIFICANTLY HIGHER EXPENSES THAN NON-BENEFICIARY FAMILIES. ALSO, THE PROGRAM COLLABORATES TO ELEVATE THE PROPORTION OF CHILDREN AND YOUTH WITH NORMAL CORPORAL MASS INDEX, AND INCREASES THE PROPORTION OF ADULTS WITH OBESITY PROBLEMS - THESE RESULTS CAN BE INDIRECTLY ASSOCIATED.

\section{PALAVRAS-CHAVE:}

Programa Bolsa Família; Consumo de alimentos; Insegurança alimentar.

Revista Brasileira de Monitoramento e Avaliação | Número 3 | Janeiro-Junho de 2012 


\section{Introdução}

O Brasil sempre foi considerado um país extremamente desigual, estando no topo do ranking das nações com maior disparidade na distribuição de renda do mundo. No entanto, desde o início dos anos 2000 tem passado por significativa transformação em suas características distributivas, apresentando notável progresso em seus indicadores econômicos e sociais, principalmente no que diz respeito à concentração de renda e pobreza.

Diversos estudos têm sido desenvolvidos pela literatura especializada sobre os fatores que influenciaram esse comportamento positivo do País. Os resultados indicam a reestruturação do mercado de trabalho, o desenvolvimento econômico e a expansão dos programas sociais, especialmente os de transferência monetária, como os fatores que mais colaboraram com essa evolução.

Quanto aos programas de transferência condicionada de renda, o Bolsa Família é apontado como o principal deles, sendo responsável por grande parcela do orçamento social do governo federal e visto como um dos instrumentos fundamentais para a redução das disparidades existentes no Brasil, uma vez que beneficia famílias pobres e extremamente pobres com o objetivo de combater a fome e promover a segurança alimentar e nutricional dos beneficiados.

Um dos resultados esperados pela aplicação desta política pública seria o aumento da demanda por alimentos, especialmente da cesta básica, pelas famílias mais vulneráveis da população. Esse processo levaria a uma redução dos problemas decorrentes da insegurança alimentar e, consequentemente, auxiliaria na quebra dos mecanismos de transmissão intergeracional da pobreza no País.

Não há garantias de que o benefício do programa é efetivamente gasto com alimentos. Assim, investigar a diferença do gasto no consumo de alimentos entre as famílias beneficiárias e não beneficiárias do Programa Bolsa Família (PBF) é importante para avaliar a contribuição desse programa na redução da insuficiência alimentar e promoção da segurança alimentar.

Apesar de diversos trabalhos apontarem as contribuições do PBF nas áreas de educação, saúde, mercado de trabalho e distribuição de renda, ainda existe uma lacuna quanto ao seu impacto sobre o consumo de alimentos e a segurança alimentar das famílias beneficiárias em nível nacional.

Diante disso, este trabalho tem por objetivo realizar uma avaliação de impacto do PBF no consumo de alimentos das famílias beneficiadas, com a intenção de descobrir em que medida esse programa colabora para a segurança alimentar das famílias pobres e extremamente pobres no Brasil.

A temática da pesquisa é atual e relevante, pois a população com insegurança alimentar no País ainda representa uma porcentagem 
expressiva do total de brasileiros, de modo que identificar a relação entre ser beneficiário do PBF e ter segurança alimentar pode contribuir para avaliar a eficiência do programa e verificar se os recursos gastos com essa política estão gerando efeito significativo sobre o consumo de alimento das famílias, um dos seus principais objetivos.

Para isso, utiliza-se como base de dados a Pesquisa de Orçamentos Familiares (POF) do ano de 2008/2009. Realiza-se o tratamento e a análise dos dados obtidos a partir do método de propensity score matching, em que se comparam as despesas com alimentos das famílias beneficiadas e não beneficiadas pelo programa, assim como a proporção de pessoas dentro de cada família com Índice de Massa Corporal (IMC) considerado normal, acima e abaixo do peso ideal.

O trabalho está organizado em quatro seções incluindo esta introdução. Na seção 2, são detalhadas a base de dados e a metodologia da pesquisa, bem como as variáveis utilizadas. Na seção 3, analisam-se os resultados da estimação do modelo quanto ao consumo de alimentos e o status nutricional das famílias. Finalmente, na seção 4, são apresentadas as conclusões.

\section{Materiais e Métodos}

\subsection{BASE DE DADOS E CARACTERIZAÇÃO DA AMOSTRA}

A partir dos dados da POF do período 2008/2009, selecionou-se uma amostra de 49.514 famílias $^{3}$, em que 8.544 delas são beneficiárias do PBF, ou seja, 17,3\% do universo pesquisado. $O$ valor médio mensal recebido pelas famílias é de $\mathrm{R} \$ 89,86$ e o tempo médio anual de recebimento do benefício é de 11,2 meses. A renda proveniente do programa representa, em média, $21,9 \%$ do rendimento total das famílias beneficiárias.

Comparando as famílias beneficiadas e não beneficiadas pelo programa quanto a algumas características da composição familiar e do domicílio, a variável que se destaca é a renda per capita mensal média, que entre beneficiários do programa é de $\mathrm{R} \$ 171,32$ (rendimento monetário descontado o valor do benefício) e entre os não beneficiários é de $R \$ 816,89$, ou seja, 4,8 vezes maior. Já a renda não monetária dos não beneficiários ( $R \$ 123,74)$ é, em média, 2,3 vezes maior que a dos beneficiários (R\$52,92).

3 Foram selecionadas apenas as famílias que possuíam todas as informações necessárias para a caracterização dos beneficiários e não beneficiários do PBF, bem como para a realização da análise de impacto, ou seja, excluíram-se as famílias cujos questionários faltavam respostas para qualquer uma das variáveis empregadas neste trabalho, como: dados sobre o chefe do domicílio, gastos com alimentação, peso e altura dos membros da família, etc. Desta forma, utiliza-se no trabalho uma subamostra da amostra efetiva da POF 2008/2009.

Revista Brasileira de Monitoramento e Avaliação | Número 3 | Janeiro-Junho de 2012 
Em relação às características familiares, nota-se que as famílias beneficiárias são maiores que as não beneficiárias. Enquanto o número médio de pessoas é de 4,71 nas famílias atendidas pelo programa, nas outras famílias a média é de 3,18 pessoas. 0 mesmo ocorre com o número médio de filhos: 2,43 entre as beneficiadas e 1,17 entre as não beneficiadas. Já o número de crianças e adolescentes é de 1,58, em média, nas famílias beneficiárias e de 0,58 nas não beneficiárias, enquanto o número de jovens é de 0,21 e 0,08, respectivamente ${ }^{4}$.

Quanto ao perfil do chefe da família, a percentagem de homens é ligeiramente mais elevada entre os beneficiários (70,4\%), no entanto a percentagem de brancos $(23,0 \%)$, a média de idade (42,75 anos) e de anos de estudo (4,0 anos) são mais baixas.

As características dos domicílios refletem grande dificuldade de acesso das famílias beneficiadas a serviços básicos. Enquanto 92,6\% dos domicílios não beneficiários do programa possuem água encanada, entre os atendidos pelo PBF o percentual é de apenas $75,7 \%$. Já a porção de famílias beneficiadas que tem acesso a esgoto canalizado $(17,8 \%)$ não chega à metade do percentual das famílias não beneficiadas (40,5\%). Quanto aos serviços de coleta de lixo e pavimentação de rua, também se pode notar uma disparidade entre as famílias atendidas e não atendidas pelo programa. O acesso à rede elétrica é o serviço com atendimento mais uniforme. Além disso, os domicílios das famílias que são atendidas pelo programa possuem menos cômodos e banheiros que as outras.
Quanto à localização das famílias, a grande parte das beneficiadas, $78,3 \%$, situa-se nas regiões Nordeste $(59,9 \%)$ e Norte $(18,4 \%)$ do Brasil, enquanto entre as não beneficiadas essa percentagem não passa de $45 \%$. Por outro lado, a percentagem de famílias residentes em áreas urbanas e regiões metropolitanas é menor nas famílias beneficiárias em relação às não beneficiárias.

\subsection{METODOLOGIA}

Para realizar uma análise de impacto de qualquer política ou programa, é necessário observar o que teria acontecido com o indivíduo que foi beneficiado caso ele não tivesse recebido o benefício. Como não se pode observar o beneficiário nas duas situações (recebendo e não recebendo o benefício), deve-se considerar um indivíduo com as mesmas características do beneficiário, mas que no mesmo período não recebeu o benefício, ou seja, comparar o grupo de tratamento com o grupo de controle.

Esse contrafactual é obtido mediante aleatorização dos potenciais beneficiários, um método estatístico que garante que os grupos de tratamento e controle sejam iguais em características observáveis e não observáveis, eliminando assim qualquer viés de mensuração do verdadeiro impacto do programa.

Dado que os benefícios do PBF não foram distribuídos de forma aleatória, pois existem critérios de elegibilidade, deve-se utilizar métodos quase-experimentais.

Suponha uma política que tenha por objetivo o aumento do consumo de alimentos. Há 
duas situações: $\mathrm{D}=1$ para o caso das famílias participarem da política e $D=0$, caso contrário. O resultado observado para a variável de interesse $\left(Y_{i}=\right.$ consumo de alimentos) pode ser representado por: $Y_{i}=D . Y_{1 i}+(1-D) \cdot Y_{0 i} \cdot O$ impacto médio da política sobre a família beneficiada é dado por:

$\Delta_{i}=Y_{1 i}-Y_{0 i}$ e $\Delta_{i}=E\left(\Delta_{i} \mid D=1\right)=E\left(Y_{1 i}-Y_{0 i} \mid D=1\right)$

\section{(1)}

Em que $E(\cdot \mid D=1)$ refere-se ao valor esperado, condicional à participação no programa social. Na literatura de avaliação, essa expressão é denominada de efeito médio do tratamento sobre os tratados (ATT) (average treatment effect on treated) e captura o efeito causal do programa para a subpopulação dos tratados 5 .

Comparando as famílias que receberam o benefício com aquelas que não o receberam, obtem-se uma medida aproximada do impacto do benefício sobre a variável considerada, mas essa medida apresenta um viés, já que uma simples comparação entre os grupos pode refletir diferenças pré-programa. $O$ viés é a diferença entre o resultado dos tratados caso não tivessem sido tratados e o resultado dos controles, que de fato não receberam o tratamento.
De acordo com Heckman et al. (1997), esse viés pode ser resultado de três fatores: falta de suporte comum, viés nas características observáveis $\left(X_{i}\right)$ entre os tratados e não tratados e viés de seleção, que é proveniente de características não observáveis que influenciam o resultado mesmo após o condicionamento em $X_{i}$.

Para a resolução do problema de viés nas características observáveis, Rosenbaum e Rubin (1983) desenvolveram, a partir do pareamento de características observáveis dos indivíduos do grupo amostral, o método conhecido como Propensity Score Matching (PSM).

Nesta técnica, leva-se em consideração as características observáveis $\left(X_{i}\right)$ que afetam a decisão do indivíduo de participar ou não do programa, uma vez que os indivíduos com características observáveis idênticas possuem a mesma probabilidade de receber o benefício.

Assim, considera-se o pressuposto de independência condicional aos atributos observáveis dos grupos de tratamento e controle. Isto significa que se apenas os atributos observáveis causam viés nas medidas de impacto, então a estimativa quase-experimental fornecerá uma boa medida de impacto. Por

4 São considerados como crianças e adolescentes os indivíduos com idade entre 0 e 15 anos completos e como jovens aqueles com idade superior a 15 e inferior a 18 anos.

5 (HECKMAN et al., 1997.)

Revista Brasileira de Monitoramento e Avaliação | Número 3 | Janeiro-Junho de 2012 
outro lado, se as variáveis não observáveis que são relacionadas com o recebimento do programa afetam o impacto, então ainda poderá haver um viés na medida de impacto.

Dessa forma, o efeito do programa sobre as famílias (equação 1) pode ser reescrito como:

$\Delta=E\left(Y_{1 i} \mid X_{i,} D=1\right)-E\left(Y_{0 i} \mid X_{i} D=0\right)$

Em que:

$E\left(Y_{1 i} \mid X_{i,} D=1\right)$ refere-se ao valor esperado, condicional ao conjunto de características observáveis e à participação no programa social;

$E\left(Y_{0 i} \mid X_{i} D=0\right)$ refere-se ao valor esperado, condicional ao conjunto de características observáveis e à não participação no programa social.

Entretanto, quanto mais características são utilizadas para comparar os grupos, maior será o número de observações necessárias para que se possa realizar o pareamento entre tratados e controle.

O propensity score matching foi desenvolvido para resolver o problema do dimensionamento do pareamento. Pode ser implementado por uma única variável de controle, o propensity score $P(X)$, definido como a probabilidade condicional de um indivíduo receber benefício, dadas suas características observáveis: $P(X)=\operatorname{Pr}(D=1 \mid X)^{6}$.

Assim, elimina-se o problema da multidimensionalidade do pareamento mediante o propensity score, dado que $P(X)$ é uma probabili- dade $(0<P(X)<1)$. Pode-se então substituir $X_{i}$ (vetor das características observáveis) pelo escalar $P(X)$ na equação (2):

$E(Y 1 i-Y O i \mid D=1, P(X))=E(Y i \mid D=1, P(X))-$ $E(Y i \mid D=0, P(X))$

(3)

A condição $0<P(X)<1$ assegura que para cada grupo de tratamento existirá um grupo de controle correspondente, com valores similares de $X_{i}$ ou seja, garante o suporte comum, condição necessária para a utilização do $\mathrm{PSM}^{7}$.

Cabe destacar que, segundo Becker e Ichino (2002), o método do escore de propensão não elimina o viés gerado pelos fatores não observáveis, pode apenas reduzi-lo, dependendo das variáveis de controle utilizadas no pareamento.

Já Heckman et al. (1998) mostram que o método de pareamento baseado no escore de propensão não necessariamente reduz o viés e afirmam que a vantagem do uso do $P(X)$ é a simplicidade na estimativa.

Dadas as amostras dos tratados e não tratados, estima-se uma regressão logit (ou probit) para obter a probabilidade dos indivíduos participarem do programa a partir de suas características observáveis $\left(X_{i}\right)$. Nessa regressão, a variável dependente é uma dummy que assume valor 1 para o caso do grupo de tratamento (famílias beneficiadas) e zero para o grupo de controle (famílias não beneficiadas).

Pela estimativa do $P(X)$, são obtidos subgrupos dentro do grupo de controle que pos- 
suem probabilidades semelhantes às das famílias do grupo de tratamento. Testa-se então a média de cada variável dentro de cada bloco do $P(X)$ a fim de identificar se existem diferenças. Se todos os testes mostrarem que a média não difere significantemente, define-se um número de blocos ou estratos e realiza-se a estimação do efeito do tratamento mediante os métodos de pareamento ${ }^{8}$.

Neste trabalho é utilizado o algoritmo de pareamento de Kernel. A escolha por esse estimador não paramétrico ocorreu devido à sua metodologia, que calcula a diferença de média entre tratados e controle ponderando pelo $P(X)$. Dessa forma, famílias do grupo de controle que são muito semelhantes a famílias do grupo de tratamento, ou seja, que apresentem elevado $P(X)$, recebem peso maior no momento da estimação do efeito do tratamento, uma vez que representam melhor as famílias do tratamento. Além disso, o fato de empregar todas as observações da amostra faz com que sua variância seja menor que a dos outros estimadores ${ }^{9}$.
Assim, o impacto do PBF sobre os gastos com alimentação das famílias beneficiadas (ATT) foi estimado a partir da comparação entre os beneficiários e os não beneficiários do programa, escolhidos por suas características observáveis a partir da estimação do propensity score e pareados por meio do algoritmo de Kernel.

\subsection{DESCRIÇÃO DAS VARIÁVEIS}

O conjunto de famílias beneficiárias do PBF é considerado como grupo de tratamento. Já o grupo de controle é constituído por famílias que não recebem o benefício, mas que apresentam características semelhantes às dos beneficiários.

Com a intenção de delimitar o número de famílias a serem analisadas e realizar uma comparação apenas entre famílias semelhantes, realizou-se um corte na amostra, de modo que na análise são consideradas apenas as famílias cuja renda mensal per capita ${ }^{10}$ é superior a $\mathrm{R} \$ 69,00$ e inferior a $\mathrm{R} \$ 273,00 .{ }^{11}$ Esse valor é maior que o estabelecido como limite

6 (ROSENBAUM; RUBIN, 1983.)

7 (HECKMAN et al., 1997.)

8 Para mais detalhes ver Caliendo e Kopeinig (2008).

9 (CALIENDO; KOPEINIG, 2008.)

10 (CALIENDO; KOPEINIG, 2008.)

11 Rendimento monetário descontado o valor do benefício do PBF.

Revista Brasileira de Monitoramento e Avaliação | Número 3 | Janeiro-Junho de 2012 
( $R \$ 137,00)$ ao recebimento do benefício, pois o PBF chega a quase $100 \%$ da população em situação de pobreza e extrema pobreza ${ }^{12}$, de modo que pode não haver um contrafactual ao se considerar o mesmo corte de renda do programa.

Assim, o corte foi estabelecido a partir do valor mínimo para ser considerado pelo programa como pobre ${ }^{13}(R \$ 69,00)$ e o valor médio da renda per capita mensal das famílias beneficiárias ( $R \$ 171,00)$. Além disso, foram consideradas apenas as famílias que possuem filhos com idade inferior a 18 anos, uma vez que de acordo com os critérios do PBF, as famílias pobres são elegíveis ao pro- grama somente se possuírem filhos nessa faixa etária.

Como visto anteriormente, para obter-se um grupo de controle que seja representativo do grupo de tratamento (beneficiados), é necessário que as características observáveis dos dois grupos sejam as mais semelhantes possíveis. Neste trabalho, utilizam-se como controles variáveis relacionadas à pobreza, dado que o público-alvo do PBF é formado por famílias nessa situação. Emprega-se no modelo características do chefe do domicílio, da família e da residência, além de dummies geográficas para diferenciar regiões, área metropolitana, urbana e rural (tabela 1).

\section{TABELA 1: VARIÁVEIS DE CONTROLE UTILIZADAS NO MODELO}

\begin{tabular}{|c|c|}
\hline VARIÁVEL & DESCRIÇÃO \\
\hline renda_liq_pc & Renda líquida mensal per capita (descontado o valor do benefício). \\
\hline renda_nm_pc & Renda não monetária mensal per capita. \\
\hline sexo_chefe & Dummy para sexo do chefe do domicílio (homem=1; mulher=0). \\
\hline raca_chefe & Dummy para raça do chefe do domicílio (branco=1; não branco=0). \\
\hline idade_chefe & Idade do chefe do domicílio. \\
\hline anos_est_chefe & Anos de estudo do chefe do domicílio. \\
\hline gravidez & Dummy para existência de grávidas no domicílio (sim=1; não=0). \\
\hline n_jovens & Número de filhos com idade superior a 15 anos e inferior a 18 anos. \\
\hline n_crianças & Número de filhos com idade igual ou inferior a 15 anos. \\
\hline n_comodos & Número de cômodos no domicílio. \\
\hline n_banheiros & Número de banheiros no domicílio. \\
\hline agua_can & Dummy para água canalizada ( $\operatorname{sim=1;}$ não=0). \\
\hline esgoto_esc & Dummy para rede de escoamento sanitário ( $\operatorname{sim=1;}$ não=0). \\
\hline eletricidade & Dummy para rede de energia elétrica (sim=1; não=0). \\
\hline rua_pav & Dummy para rua pavimentada ( $\operatorname{sim}=1 ;$ não=0). \\
\hline coleta_lixo & Dummy para existência do serviço de coleta de lixo (sim=1; não=0). \\
\hline Norte & Dummy para região Norte ( $\operatorname{sim}=1 ;$ não=0). \\
\hline Nordeste & Dummy para região Nordeste (sim=1; não=0). \\
\hline Sul & Dummy para região Sul (sim=1; não=0). \\
\hline Sudeste & Dummy para região Sudeste ( $\operatorname{sim}=1 ;$ não=0). \\
\hline metrop & Dummy para área metropolitana (sim=1; não=0). \\
\hline urbano & Dummy para localização do domicílio (urbano=1; rural=0). \\
\hline
\end{tabular}


Diante do objetivo do trabalho, de analisar a diferença no consumo de alimentos entre famílias beneficiárias e não beneficiárias do PBF, utiliza-se como variável de interesse (dependente) a despesa com alimentação, que é o somatório de todo gasto familiar com a aquisição de alimentos para consumo dentro do domicílio, expresso em reais (R\$), deflacionado e anualizado.
Além disso, faz-se a decomposição do gasto com alimentação em diversas categorias, de forma a analisar a diferença entre os tipos de alimentos consumidos pelas famílias beneficiárias e não beneficiárias. A tabela 2 apresenta as variáveis dependentes utilizadas na estimação dos gastos com alimentação. As agregações foram feitas baseadas na metodologia da POF 2008/2009.

\section{TABELA 2: VARIÁVEIS DEPENDENTES: CATEGORIAS DE GASTOS COM}

ALIMENTAÇÃO

\begin{tabular}{|c|c|}
\hline VARIÁVEL & DESCRIÇÃO \\
\hline Grãos & Despesa c/ aquisição de grãos e cereais, como: arroz, feijão, milho e aveia. \\
\hline Legumes & $\begin{array}{l}\text { Despesa c/ aquisição de legumes, verduras, tubérculos e raízes, como: batata, cenoura, mandioca, } \\
\text { cebola, alface e tomate. }\end{array}$ \\
\hline Massas & Despesa c/ aquisição de massas e farinhas, como: macarrão, farinha de trigo e fubá. \\
\hline Castanhas & Despesa c/ aquisição de castanhas e cocos, como: pinhão, amêndoa, avelã, noz e coco. \\
\hline Frutas & Despesa c/ aquisição de frutas, como: banana, maçã, mamão, laranja e melancia. \\
\hline Doces & $\begin{array}{l}\text { Despesa c/ aquisição de doces e açúcares, como: açúcar refinado, chocolate em pó, mel, gelatina, } \\
\text { bala e sorvete. }\end{array}$ \\
\hline Enlatados & $\begin{array}{l}\text { Despesa c/ aquisição de enlatados, conservas, condimentos e molhos, como: azeitona, sal, vinagre } \\
\text { e molho de tomate. }\end{array}$ \\
\hline Carnes & $\begin{array}{l}\text { Despesa c/ aquisição de carnes e vísceras bovina, suína, de carneiro, etc., in natura e processadas, } \\
\text { como: filé mignon, hambúrguer, presunto e linguiça. }\end{array}$ \\
\hline Pescados & $\begin{array}{l}\text { Despesa c/ aquisição de pescados marinhos e de água doce, como: peixe, camarão, ostra, rã, tarta- } \\
\text { ruga e caramujo. }\end{array}$ \\
\hline Aves & Despesa c/ aquisição de carnes e ovos de aves, como: frango, peru, pato e avestruz. \\
\hline Leite & Despesa c/ aquisição de leite e derivados, como: queijo, manteiga e iogurte. \\
\hline Panificados & Despesa c/ aquisição de panificados, como: pão, biscoito, bolacha, bolo e rosca. \\
\hline Bebidas não alcoólicas & Despesa c/ aquisição de bebidas não alcoólicas, como: água, suco, refrigerante, café e chá. \\
\hline Bebidas alcoólicas & Despesa c/ aquisição de bebidas alcoólicas, como: cerveja, vinho e aguardente. \\
\hline Óleos e gorduras & Despesa c/ aquisição de óleos e gorduras, como: azeite, óleo de soja, gordura vegetal e animal. \\
\hline Outros produtos & $\begin{array}{l}\text { Despesa c/ aquisição de produtos preparados, semiprontos ou agregados, como: sanduíches, mar- } \\
\text { mita e cesta de café da manhã. }\end{array}$ \\
\hline Despesa c/ alimentação & Somatório das despesas com todos os tipos de alimentos consumidos no domicílio. \\
\hline
\end{tabular}

Fonte: Elaboração da autora.

12 (PNUD, 2007).

13 Esse critério vigorou entre julho/2008 e agosto/2009, para mais detalhes ver Baptistella (2012). Com esse corte foram excluídas 3.744 observações, pois não se conseguiu construir um grupo de controle que pudesse ser considerado um bom contrafactual para as famílias extremamente pobres (com renda mensal per capita inferior a $\mathrm{R} \$ 69,00$ ) beneficiadas pelo PBF.

Revista Brasileira de Monitoramento e Avaliação | Número 3 | Janeiro-Junho de 2012 
Essas variáveis serão utilizadas tanto expressas em reais ( $R \$$ ), anualizadas e deflacionadas quanto em termos percentuais (\%), em relação à despesa total com alimentação, ou seja, o quanto o gasto com cada categoria de alimento representa na despesa total das famílias com todos os tipos de alimentos.

Espera-se que, em relação ao grupo de controle, as famílias beneficiárias tenham uma despesa maior com alimentos básicos, como grãos, legumes, massas, frutas, leite e panificados; e não básicos, como carnes, peixes e doces, ou seja, alimentos mais caros, que não eram consumidos antes por falta de renda.

Com essas estimativas, pretende-se fazer inferências sobre o status nutricional das famílias participantes do programa, uma vez que ao estarem consumindo alimentos em maior quantidade e variedade nutricional, essas famílias têm a possibilidade de atingirem a situação de segurança alimentar.

Na tentativa de estabelecer uma relação entre o consumo adicional de alimentos e a segurança alimentar das famílias, calculou-se o IMC para cada indivíduo da família. O IMC é uma medida comumente utilizada para classificar se uma pessoa está abaixo, acima ou no seu peso ideal. É definido pelo peso em quilogramas dividido pelo quadrado da altura em metros (equação 4) 14: $^{14}$

Índice de Massa Corporal $(\mathrm{IMC})=$ Peso $(\mathrm{kg})$
A partir do valor do IMC calculado, classificou-se os indivíduos como magro, normal e obeso. As normas para essa classificação diferem entre adultos e crianças e adolescentes $^{15}$. Para os adultos, leva-se em consideração apenas o valor do IMC para enquadrar as pessoas nas categorias: abaixo do peso (IMC $<18,5)$, normal $(18,5 \leq \mid M C<25,0)$ e acima do peso $(I M C \geq 25,0)$.

Já para as crianças e adolescentes, a classificação depende do sexo e idade dos indivíduos, além da comparação dos resultados com os de outras crianças/adolescentes da mesma faixa etária e gênero. De acordo com o Centers for Disease Control and Prevention ${ }^{16}$ (CDC), essa diferença na categorização ocorre porque entre as crianças/adolescentes a quantidade de gordura corporal muda com a idade, além de ser diferente entre meninos e meninas.

Os gráficos 1 e 2 apresentam as categorias de IMC por idade e percentil para meninos e meninas, respectivamente. Cada gráfico contém um conjunto de curvas que indicam o percentil do IMC da criança/adolescente em relação a outras de mesma idade.

Considera-se abaixo do peso ideal a criança/ adolescente cujo ponto de intersecção entre idade e IMC estiver situado abaixo do $5^{\circ}$ percentil. Por outro lado, é considerada acima do peso aquela cujo ponto estiver acima do $85^{\circ}$ percentil. Já a criança/adolescente que apresentar idade e IMC entre essas duas linhas de percentis é considerada dentro do peso ideal ${ }^{17}$. 


\section{GRÁFICO 1: IMC POR IDADE E PERCENTIL PARA MENINOS}

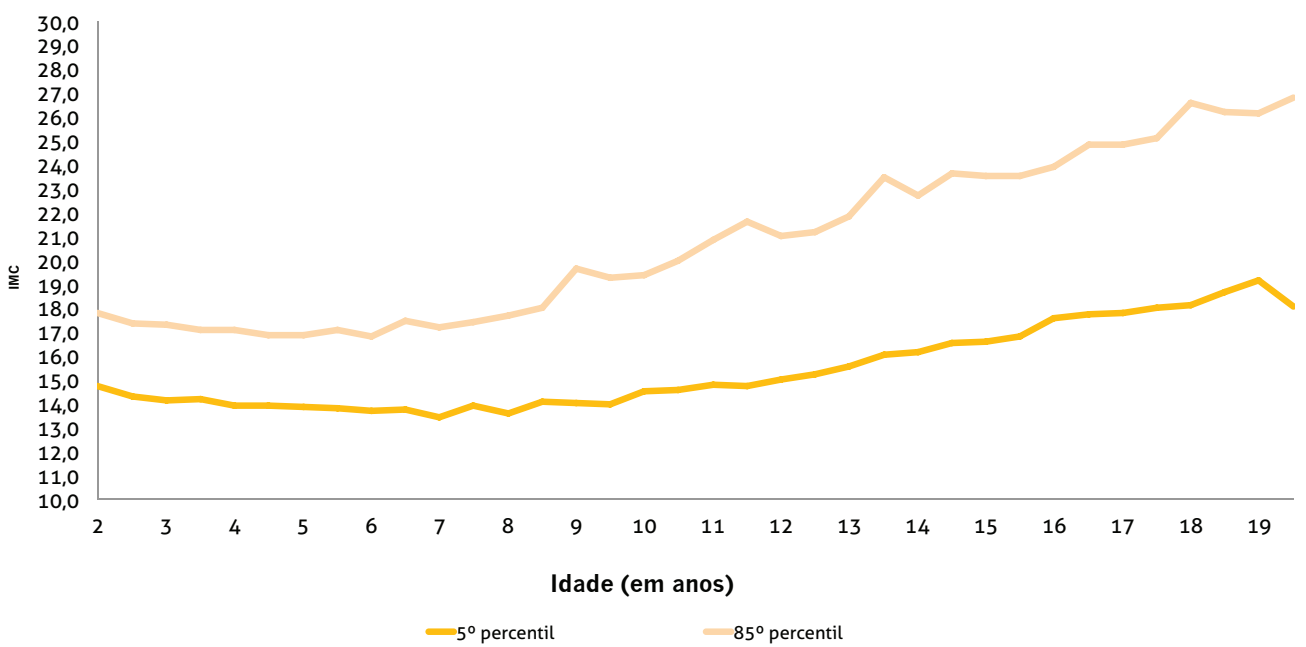

Fonte: Elaboração da autora, a partir de CDC (2002).

\section{GRÁFICO 2: IMC POR IDADE E PERCENTIL PARA MENINAS}

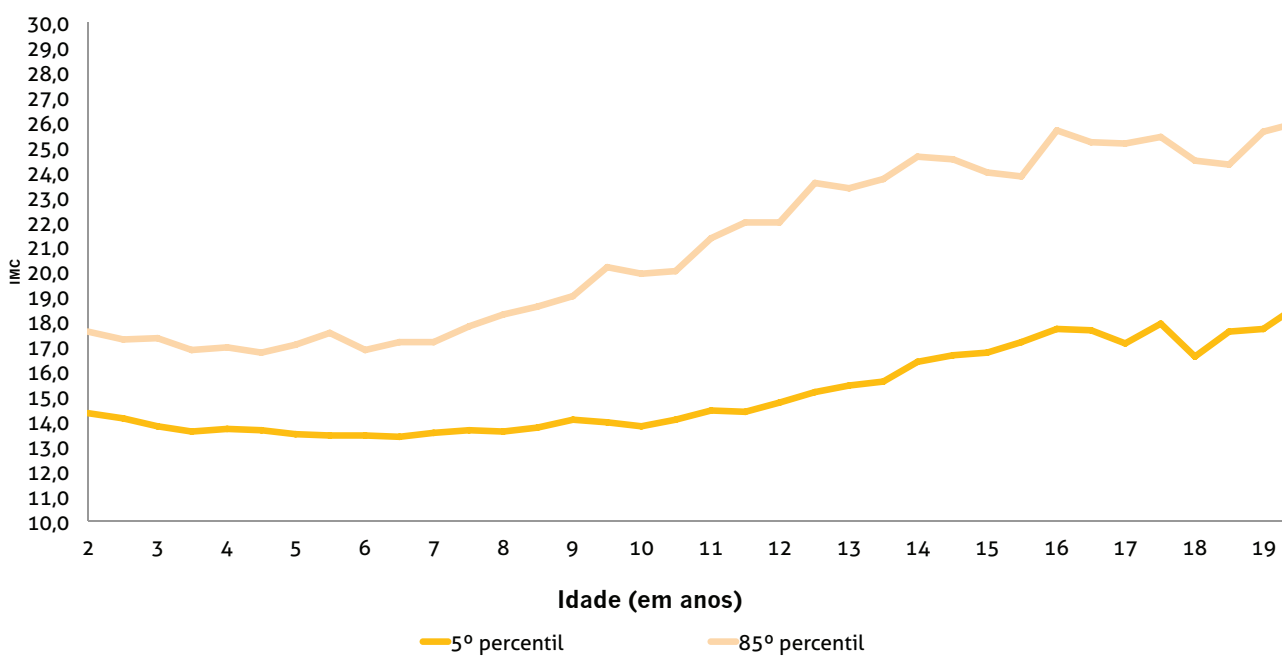

Fonte: Elaboração da autora, a partir de CDC (2002).

14 Para detalhes ver OMS (2011).

15 Nesse caso, consideram-se como crianças e adolescentes aqueles indivíduos com idade entre dois e vinte anos e adultos aqueles com idade superior a vinte anos.

16 (2011.)

17 (CDC, 2011.)

Revista Brasileira de Monitoramento e Avaliação | Número 3 | Janeiro-Junho de 2012

Avaliação de programas sociais: uma análise do impacto do Programa Bolsa Família sobre o consumo de alimentos e status nutricional das familias 


\section{OUADRO 1: VARIÁVEIS DEPENDENTES: CATEGORIAS DO IMC}

\begin{tabular}{ll} 
VARIÁVEL & DESCRIÇÃO \\
\hline Magro & Proporção de pessoas (total, adultos, crianças/adolescentes) na família abaixo do peso. \\
\hline Normal & Proporção de pessoas (total, adultos, crianças/adolescentes) na família c/ peso normal. \\
\hline Obeso & Proporção de pessoas (total, adultos, crianças/adolescentes) na família acima do peso. \\
\hline
\end{tabular}

Fonte: Elaboração da autora.

Após a classificação de cada membro da família quanto ao IMC, estimou-se a proporção de pessoas da família em cada categoria do IMC. Essas variáveis serão utilizadas como proxy para o efeito do programa sobre o status nutricional das pessoas beneficiadas (quadro 1 ).

O efeito que se espera do programa, a partir da estimação dessas variáveis, é que as famílias tratadas apresentem uma proporção menor de pessoas abaixo do peso, ou seja, que possuam uma quantidade maior de pessoas saudáveis. Assim, se essa afirmação se confirmar, sugere-se que o programa está contribuindo para a redução da insegurança alimentar nas famílias pobres brasileiras.

\section{Resultados}

\subsection{PAREAMENTO DAS OBSERVAÇÕES}

São utilizadas 9.398 observações, das quais 3.745 famílias (39,85\%) participam do PBF e compõem o grupo de tratamento, enquanto as 5.653 famílias restantes, 60,15\% dessa subamostra, não participam do programa e são consideradas como grupo de controle.

A especificação final do modelo logit de escore de propensão satisfez a hipótese do balanceamento (Balancing Hypothesis) das variáveis, ou seja, as médias de todas as variáveis não apresentaram diferença significativa entre os grupos de tratamento e controle. Além disso, os resultados dos coeficientes estimados pelo modelo para grande parte das variáveis apresentaram os sinais esperados.

A tabela 3 apresenta o efeito marginal de cada variável sobre a participação das famílias no programa. Nota-se que o aumento na renda reduz a probabilidade de participação no programa, assim como o fato do chefe da família ser do sexo masculino, branco, com mais anos de estudo e menor idade. Por outro lado, quanto mais elevado o número de jovens e crianças na família, maior a chance de participação no programa. 
TABELA 3: EFEITOS MARGINAIS DAS VARIÁVEIS SOBRE A PARTICIPAÇÃO NO PBF ESTIMADOS PELO MODELO logit

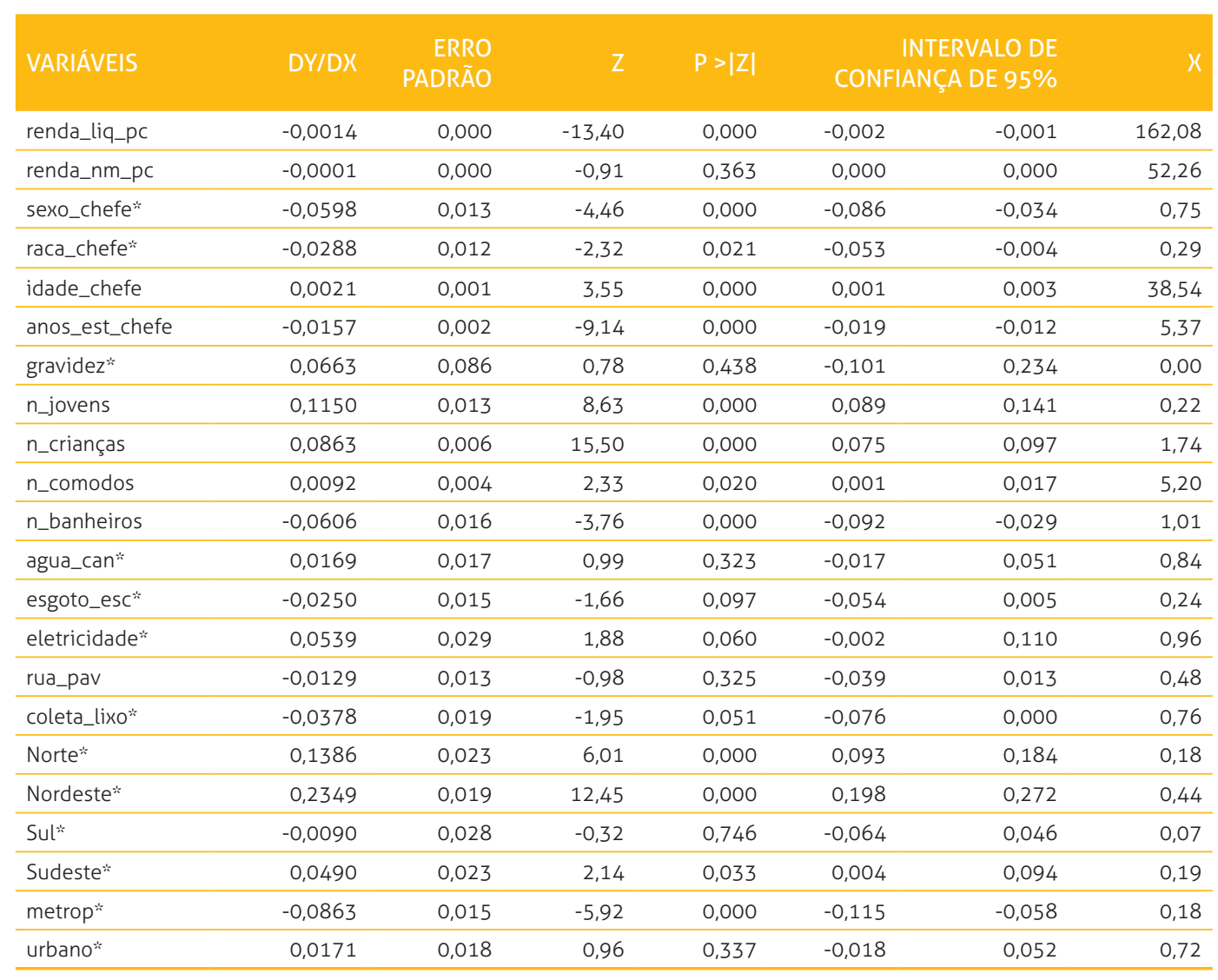

Fonte: Elaboração da autora, a partir de POF/IBGE (2008/2009)/Microdados.

Nota: * dy/dx é para mudança discreta da variável dummy de 0 para 1.

Quanto às características dos domicílios, destaca-se que o fato de possuir rede de escoamento sanitário e sistema de coleta de lixo, bem como o número de banheiros, reduz a probabilidade da família ser beneficiária. Já a localização dos domicílios nas regiões Nordeste, Norte e Sudeste e em áreas não metropolitanas contribuem para elevar essa possibilidade.
De fato, a característica que mais contribui para aumentar a probabilidade é situar-se nas regiões Nordeste (23,5 pontos percentuais - p.p.) e Norte (13,9 p.p.), justamente aquelas consideradas as mais pobres e desiguais do País. Já o número de jovens e de crianças aumentam em 11,5 p.p. e 8,6 p.p., respectivamente, a probabilidade de participação no $\mathrm{PBF}$, o que condiz com os critérios de concessão dos benefícios do programa.

Revista Brasileira de Monitoramento e Avaliação | Número 3 | Janeiro-Junho de 2012 
Por outro lado, os fatores que mais contribuem para reduzir a probabilidade de inserção no programa são: a localização em regiões metropolitanas (8,6 p.p.), o número de banheiros no domicílio (6,1 p.p.), o chefe da família ser homem (5,98 p.p.) e de cor branca (2,9 p.p.).

Algumas variáveis incluídas no modelo não apresentaram os sinais esperados e não se mostraram estatisticamente significativas. No entanto, de acordo com Venetoklis ${ }^{18}$, isso não significa necessariamente que essas variáveis devam ser excluídas. De acordo com Rubin e Thomas $^{19}$, uma variável só deve ser excluída da análise se houver um consenso de que ela não é adequada.

Após a estimação da probabilidade de participação no programa pelo modelo logit, realizou-se o pareamento das famílias pertencentes aos grupos de controle e tratamento de acordo com essa probabilidade, dadas as características observáveis.

O método de pareamento dividiu a variação dos escores de propensão ( $p x$ ) em 12 estratos diferentes, ou seja, 12 subgrupos dentro dos grupos de controle e tratamento com valores de escores similares (com suporte comum) e que na média apresentam a mesma probabilidade de receber o benefício. A região de suporte comum é [0,0749; 0,9802] e 40 observações do grupo de controle apresentaram valores para o escore de propensão ( $p x)$ fora deste intervalo, sendo excluídas automaticamente da subamostra no momento do pareamento.

Como pode ser observado na tabela 4, todos os blocos possuem controles, ou seja, famílias que não receberam o tratamento, mas que possuem características semelhantes às que receberam e, portanto, podem ser comparadas entre si.

TABELA 4: LIMITE INFERIOR, NÚMERO DE TRATADOS E CONTROLES PARA CADA BLOCO DE $P(X)$

\begin{tabular}{rrrr} 
LIMITE INFERIOR & TRATAMENTO & CONTROLE & TOTAL \\
\hline 0,075 & 7 & 110 & 117 \\
\hline 0,100 & 202 & 1165 & 1367 \\
\hline 0,200 & 191 & 708 & 899 \\
\hline 0,250 & 277 & 653 & 930 \\
\hline 0,300 & 575 & 1106 & 1681 \\
\hline 0,400 & 153 & 244 & 397 \\
\hline 0,425 & 189 & 203 & 392 \\
\hline 0,450 & 382 & 386 & 768 \\
\hline 0,500 & 704 & 545 & 1249 \\
\hline 0,600 & 569 & 330 & 899 \\
\hline 0,700 & 335 & 120 & 455 \\
\hline 0,800 & 161 & 43 & 204 \\
\hline Total & 3.745 & 5.613 & 9.358 \\
\hline
\end{tabular}


A fim de avaliar a qualidade dos pareamentos, calcularam-se as médias para as covariadas antes e após o pareamento para os grupos de tratamento e controle, assim como o sugerido por Rosenbaum e Rubin ${ }^{20}$. Segundo Resende (2006), o objetivo desse procedimento é a verificação da existência de diferenças sistemáticas entre tratados e controles que possam resultar em estimativas viesadas.

A maior parte das variáveis apresentou redução no viés após o pareamento, ou seja, diminuíram-se as diferenças médias entre tratados e controles existentes na amostra inicial, sendo que essa queda foi superior a 50\% para 17 das 20 variáveis observadas. Apenas três variáveis: sexo do chefe da família, número de cômodos do domicílio e região Norte apresentaram aumento no viés após serem pareadas.

Portanto, com o pareamento, as diferenças entre as amostras se reduziram e os grupos se assemelharam mais, de modo que o grupo de controle pode ser considerado um bom representativo para o grupo de tratamento. Desta forma, a estimação do efeito médio do tratamento sobre os beneficiários pode ser realizada a partir das diferenças das médias entre tratados e controles.

\subsection{O IMPACTO DO PROGRAMA SOBRE AS DESPESAS COM ALIMENTAÇÃO}

A tabela 5 traz a estimativa do efeito médio do tratamento para o gasto com consumo de alimentos. Nota-se uma diferença positiva e significativa entre o grupo de tratamento e controle. $\mathrm{O}$ valor médio das despesas anuais com alimentação para as famílias beneficiárias é $R \$ 146,74$, superior à média dos gastos das famílias não beneficiárias, o que demonstra, como se esperava, um resultado positivo do PBF quanto ao consumo de alimentos pelas famílias pobres.

TABELA 5: EFEITO MÉDIO DO TRATAMENTO PARA A DESPESA COM ALIMENTAÇÃO

\begin{tabular}{rrrrr} 
No TRATADOS & No CONTROLES & ATT* & DESVIO PADRÃO & T*** $^{*}$ \\
3.745 & 5.613 & 146,74 & 60,56 & $2,423^{\text {****** }}$ \\
\hline
\end{tabular}

Fonte: Elaboração própria, a partir de POF/IBGE (2008/2009)/Microdados.

Notas: * Valor em real (R\$). ** Estatística t baseada no erro padrão calculada pelo método de bootstrap (50 repetições). * *** Significativo a $5 \%$.

18 (2004 apud RESENDE; OLIVEIRA, 2008.)

19 (1996 apud CALIENDO; KOPEINIG, 2008.)

20 (1985 apud CALIENDO; KOPEINIG, 2008.)

Revista Brasileira de Monitoramento e Avaliação | Número 3 | Janeiro-Junho de 2012 
Dado esse acréscimo no consumo de alimentos, resultante da renda adicional proveniente do $\mathrm{PBF}$, investiga-se a alocação das despesas das famílias entre as diversas categorias de alimentos (tabela 6). Destaca-se que as famílias beneficiárias gastam em média, anualmente, $R \$ 43,26$ a mais que as famílias não beneficiadas com o consumo de grãos e cereais. Já a despesa com a aquisição de aves e ovos aparece em seguida, sendo $R \$ 42,46$ superior entre os beneficiários. Quanto ao dispêndio com carnes, panificados, legumes, óleos e bebidas não alcoólicas, a diferença é de $R \$ 35,29$, $R \$ 23,18$, $R \$ 13,76, R \$ 11,10$ e $R \$ 9,37$ a mais, respectivamente.

Portanto, pode-se concluir que as famílias atendidas pelo programa apresentaram gastos mais elevados e significativos com o consumo de vários tipos de alimentos, principalmente com aqueles que compõem a cesta básica brasileira ${ }^{21}$.

Dada a grande disparidade regional existente no País quanto à distribuição de renda, pobreza e segurança alimentar, principalmente entre as regiões Norte/Nordeste e Sul/Sudeste, foi estimado também o impacto do PBF sobre o consumo de alimentos observando essas regiões (tabela 7).

Os resultados para as famílias residentes nas regiões Norte e Nordeste mostram que o gasto com alimentação das famílias que são atendidas pelo programa é $R \$ 192,84$

TABELA 6: EFEITO MÉDIO DO TRATAMENTO PARA OS COMPONENTES DA DESPESA COM ALIMENTAÇÃO

\begin{tabular}{lrrr} 
COMPONENTES DA ALIMENTAÇÃOO & ATTi & DESVIO-PADRÃO & Tï \\
Grãos & 43,26 & 17,99 & $(2,404)^{* * *}$ \\
\hline Legumes & 13,76 & 5,67 & $(2,427)^{* * *}$ \\
\hline Massas & 13,02 & 9,46 & $(1,377)$ \\
\hline Castanhas & $-1,09$ & 3,50 & $(-0,311)$ \\
\hline Frutas & $-0,88$ & 3,66 & $(-0,239)$ \\
\hline Doces & 9,49 & 6,60 & $(1,438)$ \\
\hline Enlatados & $-3,76$ & 4,35 & $(-0,865)$ \\
\hline Carnes & 35,29 & 19,82 & $(1,781)^{* \cdots * *}$ \\
\hline Pescados & $-11,73$ & 11,57 & $(-1,014)$ \\
\hline Aves & 42,46 & 10,69 & $(3,972)^{* *}$ \\
\hline Leite & $-9,36$ & 9,85 & $(-0,950)$ \\
\hline Panificados & 23,18 & 7,93 & $(2,922)^{* *}$ \\
\hline Bebidas não alcoólicas & 9,37 & 6,00 & $(1,651)^{* \cdots * *}$ \\
\hline Bebidas alcoólicas & $-5,74$ & 4,63 & $(-1,239)$ \\
\hline Óleos e gorduras & 11,10 & 5,53 & $(2,008)^{* * *}$ \\
\hline
\end{tabular}

Fonte: Elaboração própria, a partir de POF/IBGE, 2008/2009 (Microdados). 
superior ao das que não são atendidas, valor $31,4 \%$ maior do que o calculado para o Brasil como um todo (R\$146,74). Entre os componentes da alimentação, as famílias beneficiárias em relação às não beneficiárias têm gastos mais altos com grãos ( $R \$ 61,23)$, carnes $(R \$ 46,41)$, aves $(R \$ 43,54)$, panificados ( $R \$ 35,99)$ e legumes ( $R \$ 13,75)$ e em contrapartida gastos mais baixos com bebidas não alcoólicas (R\$9,37).

\section{TABELA 7: EFEITO MÉDIO DO TRATAMENTO PARA OS COMPONENTES DA DESPESA COM ALIMENTAÇÃO POR MACRORREGIÕES: NORTE/NORDESTE E SUL/SUDESTE}

\begin{tabular}{|c|c|c|}
\hline COMPONENTES DA ALIMENTAÇÃO & NORTE/NORDESTE & SUL/SUDESTE \\
\hline \multirow[t]{2}{*}{ Grãos } & 61,23 & 28,22 \\
\hline & $(2,680) *$ & $(0,785)$ \\
\hline \multirow[t]{2}{*}{ Legumes } & 13,75 & 17,91 \\
\hline & $(2,203) * *$ & $(1,523)$ \\
\hline \multirow[t]{2}{*}{ Massas } & 9,81 & 22,21 \\
\hline & $(0,772)$ & $(1,327)$ \\
\hline \multirow[t]{2}{*}{ Castanhas } & $-1,50$ & $-0,82$ \\
\hline & $(-0,238)$ & $(-0,756)$ \\
\hline \multirow[t]{2}{*}{ Frutas } & $-3,32$ & 0,00 \\
\hline & $(-0,558)$ & $(-0,000)$ \\
\hline \multirow[t]{2}{*}{ Doces } & 11,39 & 21,92 \\
\hline & $(1,570)$ & $(1,404)$ \\
\hline \multirow[t]{2}{*}{ Enlatados } & $-3,49$ & 1,15 \\
\hline & $(-0,970)$ & $(0,113)$ \\
\hline \multirow[t]{2}{*}{ Carnes } & 46,41 & $-34,10$ \\
\hline & $(1,751) * \cdots$ & $(-0,677)$ \\
\hline \multirow[t]{2}{*}{ Pescados } & $-16,63$ & $-2,50$ \\
\hline & $(-1,079)$ & $(-0,406)$ \\
\hline \multirow[t]{2}{*}{ Aves } & 43,54 & 51,47 \\
\hline & $(3,106) *$ & $(3,664) *$ \\
\hline \multirow[t]{2}{*}{ Leite } & $-1,70$ & $-31,18$ \\
\hline & $(-0,123)$ & $(-1,143)$ \\
\hline \multirow[t]{2}{*}{ Panificados } & 35,99 & $-2,85$ \\
\hline & $(3,417) *$ & $(-0,188)$ \\
\hline \multirow[t]{2}{*}{ Bebidas não alcoólicas } & 9,37 & 20,84 \\
\hline & $(1,274)$ & $(1,353)$ \\
\hline \multirow{2}{*}{ Bebidas alcoólicas } & $-8,56$ & 3,23 \\
\hline & $(-1,807)^{* \cdots * k}$ & $(0,315)$ \\
\hline \multirow[t]{2}{*}{ Óleos } & 6,99 & 19,02 \\
\hline & $(1,318)$ & $(1,706)^{* \cdots *}$ \\
\hline \multirow[t]{2}{*}{ Alimentação total } & 192,84 & 99,27 \\
\hline & $(2,463) * \cdots$ & $(0,602)$ \\
\hline
\end{tabular}

Fonte: Elaboração da autora, a partir de POF/IBGE (2008/2009)/Microdados.

Obs.: os valores do ATT são expressos em reais (R\$). Os valores entre parênteses representam a estatística t baseada no erro padrão calculado pelo método de bootstrap (50 repetições).

Notas: *Significativo a 1\%. **Significativo a $5 \%$. ***: Significativo a $10 \%$.

21 De acordo com o Dieese (2009), a cesta básica no Brasil é composta por: arroz, feijão, batata, tomate, farinha, banana, açúcar, carne, leite, manteiga, pão francês, café em pó e óleo, sendo que a quantidade de cada alimento varia por regiões.

Revista Brasileira de Monitoramento e Avaliação | Número 3 | Janeiro-Junho de 2012 


\section{GRÁFICO 3: PROPORÇÃO DA DESPESA COM ALIMENTAÇÃO COM CADA TIPO DE ALIMENTO PARA FAMÍLIAS BENEFICIADAS}

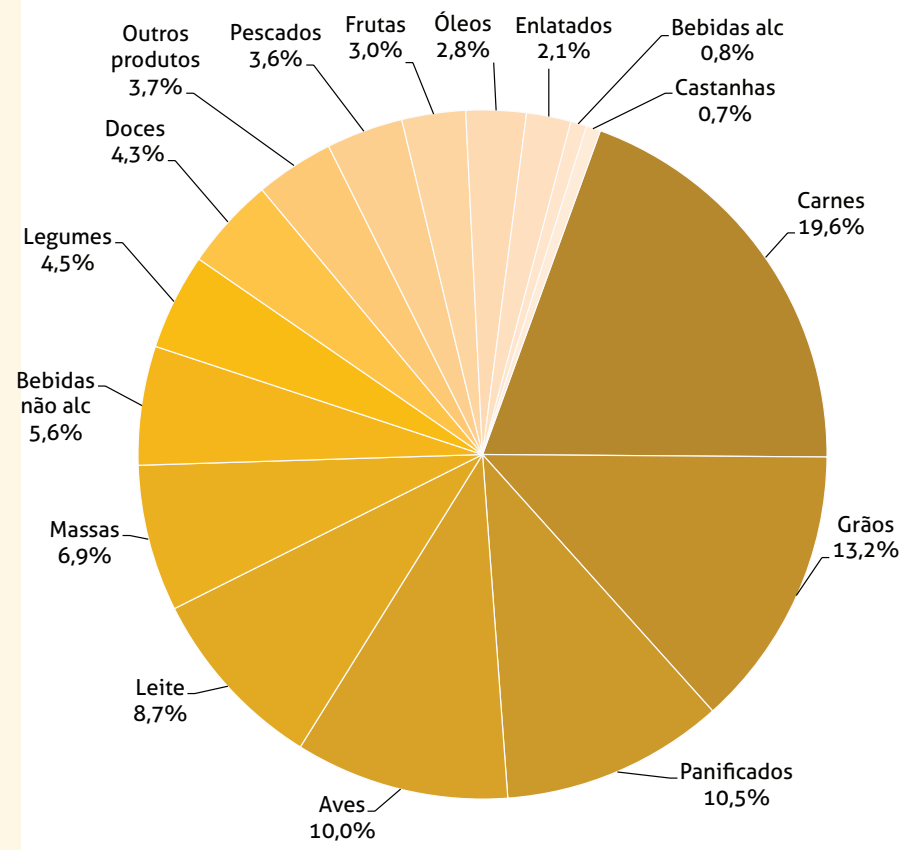

Fonte: Elaboração da autora, a partir de POF/IBGE (2008/2009)/Microdados.

No entanto, para as famílias residentes nas regiões Sul e Sudeste do País, apenas os gastos com o consumo de aves $(\mathbf{R} \$ 51,47)$ e óleos $(R \$ 19,02)$ foram maiores nas famílias participantes do PBF. Além disso, não se encontrou um impacto do programa sobre a despesa total das famílias com alimentação, uma vez que o resultado não foi estatisticamente significativo.

Comparativamente às regiões Sul e Sudeste, pode-se concluir que o impacto do PBF quanto ao consumo de alimentos é maior nas regiões Norte e Nordeste, exatamente aquelas que apresentam os piores indicadores econômicos e sociais do País e que juntas recebem mais de $60 \%$ dos benefícios do programa.

Analisando a proporção média gasta com cada tipo de alimento em relação à despe- sa total com alimentação das famílias participantes do programa (para o Brasil todo), verifica-se que a maior parcela do gasto é destinada ao consumo de carne $(19,6 \%)$, seguida por grãos (13,2\%), panificados $(10,5 \%)$, aves $(10,0 \%)$, leite $(8,8 \%)$, massas $(6,9 \%)$ e bebidas não alcoólicas (5,6\%). Já entre os componentes restantes, destaca-se que as bebidas alcoólicas representam apenas $0,8 \%$ do gasto total dessas famílias com alimentação (gráfico 3).

A fim de realizar uma comparação com as famílias não beneficiadas, estimou-se o efeito médio do tratamento sobre o consumo de alimentos a partir da proporção que o gasto com cada categoria de alimento representa em relação ao dispêndio total das famílias com alimentação (tabela 8). 


\section{TABELA 8: EFEITO MÉDIO DO TRATAMENTO PARA AS PROPORÇÕES DA DESPESA COM ALIMENTAÇÃO COM CADA TIPO DE ALIMENTO}

\begin{tabular}{lcrr} 
COMPONENTES DA ALIMENTAÇÃO & ATTi & DESVIO-PADRÃO & Tii \\
Grãos & 0,008 & 0,003 & $(2,482)^{* * * *}$ \\
\hline Legumes & 0,005 & 0,002 & $(2,694)^{* *}$ \\
\hline Massas & 0,001 & 0,003 & $(0,273)$ \\
\hline Castanhas & $-0,001$ & 0,001 & $(-1,332)$ \\
\hline Frutas & $-0,001$ & 0,002 & $(-0,732)$ \\
\hline Doces & 0,003 & 0,002 & $(1,918)^{* * * *}$ \\
\hline Enlatados & $-0,001$ & $(-0,994)$ \\
\hline Carnes & 0,010 & 0,001 & $(2,151)^{* * *}$ \\
\hline Pescados & $-0,002$ & 0,004 & $(-1,024)$ \\
\hline Aves & 0,010 & 0,002 & $(3,558)^{* *}$ \\
\hline Leite & $-0,014$ & 0,003 & $(-4,343)^{* *}$ \\
\hline Panificados & $-0,015$ & 0,003 & $(-3,723)^{* *}$ \\
\hline Bebidas não alcoólicas & 0,003 & 0,004 & $(1,234)$ \\
\hline Bebidas alcoólicas & $-0,002$ & 0,002 & $(-2,015)^{* * * *}$ \\
\hline Óleos e gorduras & 0,004 & 0,001 & $(3,594)^{* *}$ \\
\hline
\end{tabular}

Fonte: Elaboração da autora, a partir de POF/IBGE (2008/2009)/Microdados.

Notas: 'Valores expressos em termos proporcionais à despesa total com alimentação. ii Os valores entre parênteses representam a estatística t baseada no erro padrão calculado pelo método de bootstrap (50 repetições). *Significativo a 1\%. **Significativo a $5 \%$. ***:Significativo a $10 \%$.

Ao se observar apenas a proporção de adultos, verifica-se que as famílias tratadas possuem, em média, $1,8 \%$ a mais de pessoas obesas e $1,5 \%$ a menos de pessoas com peso normal. Já ao considerar somente crianças e adolescentes nas famílias, obteve-se que, em média, as famílias atendidas pelo programa têm $4,2 \%$ a mais de indivíduos com IMC normal e $1,8 \%$ a menos de obesos do que as famílias que não recebem o benefício.

Os resultados mostram que a proporção média gasta com grãos, legumes, doces, carnes, aves e óleos é mais elevada e significativa nas famílias participantes do programa, ou seja, essas famílias, comparativamente com aquelas que não participam do programa, empregam um valor maior do seu gasto total com alimentação na compra de alimentos que se enquadram nessas categorias. Em contrapartida, as proporções dos gastos com leite, panificados e bebidas alcoólicas são menores nas famílias beneficiárias do que nas não beneficiárias.

A pequena parcela da despesa destinada ao consumo de bebidas alcoólicas pode ser vista como um ponto positivo do PBF, uma vez que existe um questionamento na sociedade quanto à apropriação indevida do valor dos

Revista Brasileira de Monitoramento e Avaliação | Número 3 | Janeiro-Junho de 2012 
TABELA 9: DISTRIBUIÇÃO (\%) DOS MEMBROS FAMILIARES POR CATEGORIA DO IMC

\begin{tabular}{lrrrrrr} 
& \multicolumn{3}{c}{ FAMÍLIA } & \multicolumn{2}{c}{ ADULTOS } & \multicolumn{1}{c}{ CRIANÇAS/ADOLESCENTES } \\
\cline { 2 - 7 } IMC & TRATADOS & CONTROLES & TRATADOS & CONTROLES & TRATADOS & CONTROLES \\
Normal & 63,15 & 60,28 & 51,21 & 52,56 & 73,10 & 67,78 \\
Magro & 6,51 & 5,64 & 3,14 & 2,76 & 9,23 & 8,99 \\
Obeso & 30,34 & 34,08 & 45,65 & 44,68 & 17,67 & 23,23 \\
\hline
\end{tabular}

Fonte: Elaboração da autora, a partir de POF/IBGE (2008/2009)/Microdados.

benefícios pelos pais, mas como é verificado, essa é uma das menores proporções do gasto com alimentação das famílias beneficiárias do programa, além de ser inferior à das famílias não beneficiadas.

Vale destacar que, apesar de significativa estatisticamente, a maioria das estimativas do efeito médio do tratamento para as proporções da despesa com alimentação é tão pequena que pode não ser significativa economicamente. No entanto, a intenção dessas estimativas é investigar como as famílias distribuem seus gastos com os diversos tipos de alimentos e compará-las.

De modo geral, os resultados evidenciam um impacto positivo do PBF sobre o consumo de alimento das famílias beneficiárias, uma vez que seus gastos com alimentação são mais elevados do que os das famílias não beneficiárias, principalmente com os alimentos das categorias: grãos, aves, carnes, legumes e óleos. Isso sugere que essas famílias passaram a ingerir maior quantidade e variedade de alimentos após a entrada no programa.

\subsection{O IMPACTO DO PROGRAMA} SOBRE O STATUS NUTRICIONAL DAS FAMÍLIAS

A análise da distribuição das pessoas por categorias do IMC permite-nos avaliar o status nutricional das famílias (tabela 9). Nas beneficiárias do PBF, em média, 63,15\% das pessoas possuem IMC normal, 30,34\% são consideradas obesas e 6,51\% magras. Já nas famílias que não são atendidas pelo programa, a percentagem de pessoas com peso normal é de 60,28\%, classificadas como magras é de $5,64 \%$ e como obesas, $34,08 \%$.

Considerando apenas os adultos das famílias, a percentagem média de pessoas com peso normal e abaixo do peso se reduz, enquanto o percentual de obesos se eleva, tanto nas famílias beneficiadas quanto nas não beneficiadas. De maneira oposta, ao se levar em conta apenas as crianças e adolescentes das famílias, o percentual de obesos diminui e o de magros e com peso normal aumenta. 


\section{TABELA 10: EFEITO MÉDIO DO TRATAMENTO PARA AS CLASSIFICAÇÕES DO IMC}

$\begin{array}{llll}\text { IMC } & \text { FAMÍLIA } & \text { ADULTOS } & \text { CRIANÇAS/ADOLESCENTES } \\ \text { Normal } & 0,006 & -0,015 & 0,042 \\ & (1,209) & (-1,677) * \cdots * & (5,490) * \\ \text { Magro } & 0,005 & 0,001 & 0,005 \\ & (1,437) & (0,354) & (1,068) \\ \text { Obeso } & -0,011 & 0,018 & -0,018 \\ & (-1,994) * * & (2,198) * * & (-2,677) *\end{array}$

Fonte: Elaboração da autora, a partir de POF/IBGE(2008/2009)/Microdados.

Obs.: valores do ATT expressos em termos proporcionais. Os valores entre parênteses representam a estatística t baseada no erro padrão calculado pelo método de bootstrap (50 repetições).

Notas: * Significativo a $1 \%$. ** Significativo a $5 \%$. *** Significativo a $10 \%$.

A tabela 10 apresenta os resultados do efeito médio do tratamento para cada classificação do IMC. Destaca-se que as famílias beneficiadas pelo PBF possuem, em média, $1,1 \%$ menos pessoas obesas do que as famílias não beneficiadas. Quanto à proporção de pessoas classificadas como normais e magras, não houve diferença significativa entre essas famílias.

Analisando o efeito médio do programa por macrorregiões (tabela 11), os resultados mostram que nas regiões Norte e Nordeste as famílias tratadas possuem uma proporção um pouco maior $(0,8 \%)$ de pessoas com IMC magro do que as famílias não atendidas pelo programa, assim como 1,1\% a mais, em média, de crianças e adolescentes magras e 2,2\% a mais de adultos obesos.
Ao mesmo tempo, essas famílias apresentam, em média, $1,6 \%$ e $2,2 \%$ a menos de crianças/ adolescentes obesos e de adultos com IMC normal, respectivamente. Porém, pode-se destacar como ponto positivo que as famílias beneficiárias do PBF possuem, em média, 4,0\% a mais de crianças e adolescentes com peso ideal para a idade do que as famílias que não participam do programa nas regiões Norte e Nordeste. Já nas regiões Sul e Sudeste, as famílias beneficiárias do PBF têm, em média, 4,1\% mais pessoas com IMC normal e 3,5\% menos pessoas obesas do que as famílias não beneficiárias. Considerando-se apenas crianças e adolescentes, os resultados são similares: as famílias atendidas pelo programa apresentam, em média, 5,6\% mais indivíduos com IMC normal e 3,4\% menos obesos do que as famílias que não são atendidas. Entre os adultos não se encontrou nenhuma diferença estatisticamente significativa entre essas famílias. 
Diante desses números, sugere-se que, como nas regiões Norte e Nordeste a pobreza e os níveis de insegurança alimentar, especialmente os tipos mais graves, são mais elevados que nas demais regiões ${ }^{21}$, as famílias demandariam um tempo maior de recebimento do benefício do PBF para saírem da situação de insegurança alimentar. Ou seja, o valor do benefício, apesar de colaborar para o aumento do consumo de alimentos, não é suficiente para comprar a quantidade de alimentos necessária para que todos os membros das famílias se alimentem com a quantidade adequada para obter um IMC considerado normal e sair da situação de insegurança alimentar.
Enfim, esses resultados mostram um impacto significativo do PBF no status nutricional das famílias. Em relação às crianças e aos adolescentes, o programa contribui para elevar a proporção daquelas classificadas com peso ideal e reduzir o percentual daquelas que estão acima do peso. Ao contrário, quanto aos adultos, o programa colabora com o aumento da percentagem daqueles considerados como obesos e a diminuição dos classificados com IMC normal.

Segundo o IBGE (2010), são de grande relevância para a saúde pública no Brasil os problemas relacionados à desnutrição nos primeiros anos de vida, ao excesso de peso

\section{TABELA 11: EFEITO MÉDIO DO TRATAMENTO PARA AS CLASSIFICAÇÕES DO IMC POR MACRORREGIÕES: NORTE/NORDESTE E SUL/SUDESTE}

\begin{tabular}{|c|c|c|c|}
\hline \multirow{2}{*}{ IMC } & \multicolumn{3}{|c|}{ REGIÕES NORTE E NORDESTE } \\
\hline & FAMÍLIA & ADULTOS & CRIANÇAS/ADOLESCENTES \\
\hline \multirow[t]{2}{*}{ Normal } & $-0,001$ & $-0,020$ & 0,040 \\
\hline & $(-0,193)$ & $(-1,825)^{* \cdots \cdots}$ & $(4,086) * *$ \\
\hline \multirow[t]{2}{*}{ Magro } & 0,008 & 0,003 & 0,011 \\
\hline & $(2,250) * \cdots$ & $(0,790)$ & $(1,738) \cdots *$ \\
\hline \multirow[t]{2}{*}{ Obeso } & $-0,007$ & 0,022 & $-0,016$ \\
\hline & $(-1,106)$ & $(2,179) * *$ & $(-1,895)^{* \cdots *}$ \\
\hline \multirow[t]{2}{*}{ IMC } & Regiões Sul & & \\
\hline & Família & Adultos & Crianças/adolescentes \\
\hline \multirow[t]{2}{*}{ Normal } & 0,041 & 0,009 & 0,056 \\
\hline & $(3,525) *$ & $(0,538)$ & $(3,274) *$ \\
\hline \multirow[t]{2}{*}{ Magro } & $-0,005$ & $-0,005$ & $-0,011$ \\
\hline & $(-0,938)$ & $(-1,018)$ & $(-1,203)$ \\
\hline \multirow[t]{2}{*}{ Obeso } & $-0,035$ & $-0,006$ & $-0,034$ \\
\hline & $(-3,316) *$ & $(-0,381)$ & $(-2,233)^{\cdots * *}$ \\
\hline
\end{tabular}


e à obesidade em todas as demais idades. De acordo com os dados, há uma forte tendência de declínio da desnutrição infantil no País nos últimos anos e, por outro lado, de aumento da obesidade em todas as faixas etárias. Essa evolução está associada principalmente às melhorias observadas no poder aquisitivo das famílias de menor renda (o excesso de peso aumenta com a renda), à cobertura de serviços básicos de saúde e saneamento e às mudanças nos hábitos alimentares.

Diante disso, conclui-se que o PBF, ao promover um aumento na renda das famílias beneficiadas, colabora para que estas elevem seu consumo de alimentos, provocando uma melhora no status nutricional das crianças e adolescentes, que de modo geral passam a apresentar um peso ideal para a idade. Quanto ao aumento da obesidade entre adultos, deve-se destacar que isso não significa necessariamente uma melhora nutricional, uma vez que pode vir associada a uma alimentação inadequada. Além disso, é possível que esse efeito seja mais bem captado para as famílias que estão inseridas há mais tempo no programa, já que um intervalo de tempo maior permitiria que o aumento na quantidade e qualidade de alimentos ingeridos pelos beneficiários do programa os transferisse para um status nutricional saudável.

De modo geral, os resultados mostram que o programa contribui para elevar o consumo de alimentos das famílias beneficiárias, tirando-as assim da situação de insegurança alimen- tar. No entanto, não garante que todos os membros da família tenham uma alimentação saudável e assim passem a apresentar peso e altura ideais para a idade.

\section{Conclusão}

Este trabalho procurou medir o impacto do PBF no consumo de alimento das famílias beneficiadas e sua contribuição para o status nutricional dessas famílias, uma vez que um dos principais objetivos do programa é combater a fome e promover a segurança alimentar dos beneficiários.

A partir de um modelo logit, foram estimadas as probabilidades de participação das famílias no programa, dadas suas características observáveis. Constatou-se que o aumento na renda reduz essa probabilidade, assim como o fato do chefe da família ser do sexo masculino, branco, com mais anos de estudo e menor idade. O mesmo ocorre com as seguintes características do domicílio: possuir rede de escoamento sanitário, rua pavimentada, sistema de coleta de lixo e o número de banheiros. Por outro lado, o número de jovens e crianças eleva a chance da família participar do programa, assim como o domicílio estar localizado nas regiões Nordeste, Norte e Sudeste e em áreas não metropolitanas.

O efeito médio do tratamento forneceu um resultado positivo do PBF quanto ao consumo de alimentos: o valor médio das despesas

Revista Brasileira de Monitoramento e Avaliação | Número 3 | Janeiro-Junho de 2012 
anuais com alimentação para as famílias beneficiárias é $R \$ 146,74$ superior à média dos gastos das famílias não beneficiárias. Quanto à distribuição deste gasto adicional entre os componentes da alimentação, os resultados apontaram que as famílias atendidas pelo programa gastam mais que as outras famílias com o consumo de grãos e cereais, aves e ovos, carnes, panificados, legumes, óleos e bebidas não alcoólicas.

Considerando o efeito médio do tratamento por macrorregiões, mensurou-se que nas regiões Norte e Nordeste o impacto do programa sobre o consumo de alimentos das famílias é 31,4\% maior que no Brasil como um todo. No entanto, nas regiões Sul e Sudeste não se encontrou diferença significativa entre o consumo das famílias beneficiárias e não beneficiárias do programa.

Ao analisar a proporção média gasta com cada tipo de alimento em relação à despesa total com alimentação das famílias participantes do programa no Brasil, verificou-se ainda que o maior gasto é com carne, seguido por grãos, panificados, aves, leite, massas e bebidas não alcoólicas. Em contrapartida, os menores gastos são aqueles destinados ao consumo de bebidas alcoólicas e castanhas.

Portanto, pode-se concluir que o PBF colabora para aumentar o consumo de alimentos das famílias beneficiadas, principalmente dos alimentos que fazem parte da cesta básica brasileira, uma vez que estas famílias apresentaram gastos mais elevados e significativos do que as famílias que não são beneficiadas. Além disso, cabe destacar que as famílias atendidas pelo programa gastam uma proporção menor da despesa com alimentação no consumo de bebidas alcoólicas do que as famílias não atendidas pelo programa.

Constatou-se também que o programa auxilia na melhora do status nutricional das crianças e adolescentes, dado que entre as famílias que recebem o benefício, tanto nas regiões Norte/Nordeste quanto Sul/Sudeste, a percentagem de crianças e adolescentes com 
IMC normal é mais elevada que nas famílias que não recebem, ao mesmo tempo em que o percentual de obesos é menor. No entanto, considerando apenas a população adulta, verificou-se que nas famílias beneficiárias a proporção de obesos é maior e a de saudáveis menor (exceto nas regiões Sul/Sudeste).

Comparativamente, as regiões Norte e Nordeste apresentaram resultados desfavoráveis em relação às regiões Sul e Sudeste quanto ao status nutricional das famílias beneficiadas. Sugere-se que essa diferença decorra do fato dos níveis de pobreza e insegurança alimentar serem mais altos no Norte e Nordeste do País, de modo que o benefício do PBF, apesar de contribuir para elevar o consumo das famílias, não tem sido suficiente para garantir a segurança alimentar a todos os membros das famílias dessas regiões.

De modo geral, conclui-se que o PBF influenciou positivamente os índices de segurança alimentar registrados no Brasil nos anos 2000, uma vez que concedeu renda adicional a famílias pobres e extremamente pobres e possibilitou que estas ingerissem uma maior quantidade e variedade de alimentos, resultando na melhora do status nutricional de suas crianças e adolescentes.

Como o programa influencia também os outros tipos de gastos das famílias beneficiadas, dado que com o aumento da renda espera-se uma elevação no total das despesas, sugere-se a continuidade desta pesquisa no sentido de fazer uma comparação entre o gasto com alimentos e outros gastos da família, a fim de investigar se há alguma mudança na proporção dessas despesas a partir do recebimento do benefício.

Enfim, este trabalho contribui para avaliação de impacto do PBF, verificando que o programa está cumprindo com um dos seus principais objetivos: combater a fome e promover a segurança alimentar dos beneficiários, ou seja, o gasto público destinado a essa política social tem sido eficiente e está contribuindo para a melhoria social do País.

Revista Brasileira de Monitoramento e Avaliação | Número 3 | Janeiro-Junho de 2012 
BAPTISTELLA, J. C. F. Avaliação de programas sociais: uma análise do impacto do Bolsa Família sobre o consumo de alimentos e status nutricional das famílias. Brasília: SOF, 2012. 64 p. Disponível em: <http:// www.esaf.fazenda.gov.br/editor/ resolveuid/ bf629633c4393457f068ffb3d35256a9>. Acesso em: 3 jun. 2012.

BECKER, S. O.; ICHINO, A. Estimation of average treatment effects based on propensity scores. The Stata Journal, v. 2, n. 4, p. 358-377, 2002.

CALIENDO, M.; KOPEINIG, S. Some practical guidance for the implementation of propensity score matching. Journal of Economic Surveys, v. 22, n. 1, 2008. p. 31-72. Disponível em: <http:// onlinelibrary.wiley.com/doi/10.1111/j.14676419.2007.00527.x/pdf>. Acesso em: 27 nov. 2011.

CENTERS FOR DISEASE CONTROL AND PREVENTION (CDC). About BMI for children and teens. In: Body Mass Index. Atlanta, 2011. Disponível em: <http://www.cdc.gov/healthyweight/assessing/ bmi/index.html>. Acesso em: 26 nov. 2011.

2000 CDC growth charts for the United States: methods and development. National Center for Health Statistics. Vital Health Statistics, Washington, v. 11, n. 246, may 2002. 192 p. Disponível em: <http://www.cdc.gov/nchs/data/series/ sr_11/sr11_246.pdf>. Acesso em: 26 nov. 2011.

DEPARTAMENTO INTERSINDICAL DE ESTATÍSTICA E ESTUDOS SOCIOECONÔMICOS (DIEESE). Metodologia da cesta básica nacional. 2009. 5 p. Disponível em: <http://www.dieese.org.br/rel/ $\mathrm{rac} /$ metodologia.pdf>. Acesso em: 30 nov. 2011.
HECKMAN, J. J. et al. Matching as an econometric evaluation estimator. Review of Economic Studies, v. 65, n. 2, 1998. p. 261-294.

Matching as an econometric evaluation estimator: evidence from evaluating a job training program. Review of Economic Studies, v. 64 , n. 4, 1997. p. 605-654.

INSTITUTO BRASILEIRO DE GEOGRAFIA E ESTATÍstICA (IBGE). Pesquisa de orçamentos familiares 2008/2009 - antropometria e estado nutricional de crianças, adolescentes e adultos no Brasil. Rio de Janeiro, 2010. 130 p. Disponível em: <http://www.ibge.gov.br/ home/estatistica/populacao/condicaodevida/pof/2008_2009_encaa/pof_20082009_ encaa.pdf>. Acesso em: 22 jan. 2011.

Pesquisa de orçamentos familiares 2008/2009 - Microdados. Disponível em: <http://www.ibge.gov.br/home/estatistica/ populacao/condicaodevida/pof/2008_2009_ aquisicao/microdados.shtm>. Acesso em: 22 jan. 2011.

ORGANIZAÇÃO MUNDIAL DA SAÚDE (OMS). Body Mass Index (BMI) classification. In: Global database on body mass index. Disponível em: <http://apps.who.int/bmi/index.jsp? introPage=intro_3.html>. Acesso em: 16 ago. 2011.

PROGRAMA DAS NAÇÕES UNIDAS PARA O DESENVOLVIMENTO (PNUD). Relatório do desenvolvimento humano 2007/2008. 2007. 402 p. Disponível em: <http://www.pnud.org.br/arquivos/rdh/rdh20072008/hdr_20072008_pt_ complete.pdf>. Acesso em: 09 jun. 2007. 
RESENDE, A. C. C. Avaliando resultados de um programa de transferência de renda: o impacto do Bolsa-Escola sobre os gastos das famílias brasileiras. 2006. 115 p. Dissertação (Mestrado em Economia) - Centro de Desenvolvimento e Planejamento Regional da Faculdade de Ciências Econômicas (Cedeplar), Universidade Federal de Minas Gerais, Belo Horizonte, 2006. Disponível em: <http:// www.cedeplar.ufmg.br/economia/dissertacoes/2006/ Anne_Caroline_Costa_Resende. pdf>. Acesso em: 30 jun. 2011.
RESENDE, A. C. C.; OLIVEIRA, A. M. H. C. Avaliando resultados de um programa de transferência de renda: o impacto do Bolsa-Escola sobre os gastos das famílias brasileiras. Estudos Econômicos, v. 38, n. 2, p. 235-265, 2008. Disponível em: <http://www.scielo.br/pdf/ee/v38n2/ a02v38n2.pdf>. Acesso em: 30 jun. 2011.

ROSENBAUM, P.; RUBIN, E. D. The central role of the propensity score in observational studies for causal effects. Biometrika, n. 70, p. 41-55, 1983. Disponível em: <http://biomet.oxfordjournals.org/ content/70/1/41.full.pdf>. Acesso em: 4 fev. 2011.

Revista Brasileira de Monitoramento e Avaliação | Número 3 | Janeiro-Junho de 2012

Avaliação de programas sociais: uma análise do impacto do Programa Bolsa Família sobre o consumo de alimentos e status nutricional das famílias 